\title{
Perceived parental support in childhood and adolescence and suicidal ideation in young adults: a cross-sectional analysis of the i-Share study
}

Melissa Macalli', Marie Tournier ${ }^{1,2}$, Cédric Galéra', Ilaria Montagni', Aicha Soumare ${ }^{1}$, Sylvana M. Côté ${ }^{1,3}$ and Christophe Tzourio ${ }^{1,4^{*}}$ (D)

\begin{abstract}
Background: Suicidal ideation and suicidal risk assessment are major concerns for health professionals. The perception of a low level of parental support is a risk factor for suicidal tendencies among adolescents, but little is known about its long-term impact on the vulnerability to suicidal behavior in young adults. We investigated whether the perceived level of parental support during childhood and adolescence was associated with current suicidal ideation in young adults.

Methods: We retrieved data collected in the i-Share study from February 1st, 2013 through January 30, 2017. This cross-sectional study included 10,015 French students, aged 18-24 years that completed an on-line self-reported questionnaire about suicidal ideation in the last 12 months and their perceived parental support in childhood and adolescence. We performed multinomial logistic regressions and sensitivity analyses to assess associations between the degree of perceived parental support and the frequency suicidal thoughts, after adjusting for the main known risk factors of suicidal ideation. We employed multiple imputations to account for missing data.

Results: The study sample included 7539 female (75.7\%) and 2436 male (24.3\%) students (mean [SD] age 20.0 [1.8] years). About one in five students reported occasional suicidal thoughts ( $n=1775,17.7 \%)$ and 368 students (3.7\%) reported frequent suicidal thoughts. The adjusted multinomial logistic regression revealed a significant negative association between perceived parental support and suicidal thoughts. A lack of perceived parental support in childhood and adolescence was associated with > 4-fold elevated risk of occasional (adjusted OR, 4.55; 95\% Cl: 2.97-6.99) and nearly 9-fold elevated risk of frequent (adjusted OR, 8.58; 95\% Cl: 4.62-15.96) suicidal thoughts, compared to individuals that perceived extremely strong parental support. This association was strongest among students with no personal history of depression or suicide attempts.

Conclusions: Students that perceived low levels of past parental support had a higher risk of suicidal ideation. Past perceived parental support appeared to be a potent marker of suicidal risk in young adults. This marker should be routinely collected in studies on suicidal risk in young adults, and it could be considered an additional screening tool.
\end{abstract}

Keywords: Perceived parental support, Suicidal ideation, College students, Young adults, i-Share cohort

\footnotetext{
*Correspondence: christophe.tzourio@u-bordeaux.fr

'Inserm, Bordeaux Population Health Research Center, University of

Bordeaux, UMR 1219, F-33000 Bordeaux, France

${ }^{4}$ University of Bordeaux, 146 rue Léo Saignat, 33076 Bordeaux Cedex,

Bordeaux, France

Full list of author information is available at the end of the article
}

(c) The Author(s). 2018 Open Access This article is distributed under the terms of the Creative Commons Attribution 4.0 International License (http://creativecommons.org/licenses/by/4.0/), which permits unrestricted use, distribution, and reproduction in any medium, provided you give appropriate credit to the original author(s) and the source, provide a link to the Creative Commons license, and indicate if changes were made. The Creative Commons Public Domain Dedication waiver (http://creativecommons.org/publicdomain/zero/1.0/) applies to the data made available in this article, unless otherwise stated. 


\section{Background}

Suicide is the second leading cause of death among young adults between the ages of 15 and 29 years [1, 2], including college students [3]. The estimated prevalence of suicide ideation ranges from 6 to 12\% among college students [4-7]. A recent meta-analysis pooled 36 college student cohorts (i.e., 634,662 students) and estimated that the 12-month prevalence of suicidal ideation was 10.6\% (95\% CI: 9.1-12.3). There was no significant difference between the prevalence estimates according to European and North American nationalities [8].

Suicidal ideation is common in young adults. It is the first step on the pathway to suicide [5] and one of the main risk factors for suicide attempts and suicides [9-11]. Suicidal behaviors are the result of complex interactions between social, psychological, and environmental risk factors. Moreover, many investigators have shown that, within this etiological heterogeneity, familial contributions are potent factors. Adoption and twin studies suggested that genetic factors account only in part for transmission of suicidal behavior [12]. Suicidal behaviors have also been associated with exposure of children and adolescents to domestic violence or sexual abuse, family conflicts, parent loss, parental divorce or separation, and a family history of mood disorder or substance abuse [5, 13-15].

Some studies have suggested that low levels of perceived parental support (PPS) were associated with higher suicidal ideation in adolescents [16-18], but little is known about this relationship in young adults. In this study, we tested the hypothesis that a low level of PPS in childhood and adolescence induced a persistent impact on the vulnerability to suicidal ideation in young adults.

\section{Methods}

\section{Study population and data collection}

Our study sample comprised participants of the ongoing, internet-based, Students' Health Research Enterprise (i-Share) project, a prospective, population-based study of students in French-speaking universities and higher education institutions. Enrollment in the i-Share project started in 2013; to be eligible, a student had to be officially registered at a University or higher education institute, at least 18 years of age, able to read and understand French, and provide informed consent for participation. No compensation was given to students for completing the questionnaire on which the analyses of the current paper are based.

The i-Share protocol was approved by the "Commission nationale de l'informatique et des libertés" (CNILNational Commission of Informatics and Liberties), which ensures that data collection does not violate freedom, rights, or human privacy. No information on ethnic or racial origin was collected in i-Share.
Students were informed about the purpose and aims of the study through flyers, communications in classes, social media, and a newsletter (http://www.i-Share.fr). After formal pre-registration on the i-Share online portal, a change of password, and validation of the informed consent, students completed the self-administered baseline questionnaire. This questionnaire recorded information on the participant's health status, personal and family medical history, sociodemographic characteristics, and lifestyle habits.

For this cross-sectional study, we acquired data from a large sample of students that had participated in the i-Share cohort study between February 2013 and January 2017. Students were eligible only when they completed all items in the questionnaire. We restricted our analyses to students aged 18-24 years old, because this age range is defined as young adults, by the World Health Organization [19], and it is typically associated with major changes in a student's life.

\section{Measures \\ Outcome: Suicidal thoughts}

Suicidal thoughts were investigated with the question: In the last 12 months, how often have you thought of committing suicide (had suicidal ideation)? Participants selected one of three possible responses: (1) no suicidal thoughts, (2) occasional suicidal thoughts, and (3) frequent suicidal thoughts.

\section{Exposure variable: Perceived parental support in childhood and adolescence}

PPS was investigated with the question: During your childhood and adolescence, how would you describe the support and comfort provided by your family? Participants selected one of five different responses: (1) none, (2) low, (3) moderate, (4) strong, and (5) extremely strong.

\section{Covariates}

The following potentially confounding self-reported variables were considered in the analyses: age, gender (male, female), parents divorced or separated (yes, no), parental death (yes, no), did not live in parental home during childhood (yes, no), perceived economic status in childhood (adequate to very comfortable, difficult to very difficult), parental history of depression or anxiety (yes, no), and personal history of depression or attempted suicide (yes, no). Given the low number of students with a history of attempted suicide, the history of depression and attempted suicide were grouped into one variable.

\section{Statistical analyses \\ Descriptive analyses}

We first described the variables in the whole sample and divided individuals into three groups, according to the frequency of suicidal thoughts. Continuous variables are 
expressed as the mean $\pm \mathrm{SD}$. Categorical variables are described as the proportion (range). The Kruskal-Wallis test was used to compare the distributions of age in the three groups of suicidal thoughts. Proportions were compared with the Chi-square test.

\section{Model construction}

Unadjusted and adjusted multinomial logistic regression models were utilized to assess the relationship between PPS and the frequency of suicidal thoughts. Model convergence was systematically checked. The assumption of linearity of the logit was tested for the continuous variable, age. We also tested interactions between PPS and the covariates included in the model. The fully adjusted complete-case analysis took into account age, gender, parental divorce or separation, parental death, not living in the parental home during childhood, perceived economic status in childhood, and a personal history of depression or attempted suicide. We also conducted a sensitivity analysis in another adjusted model, which included the additional factor: parental history of depression or anxiety.

\section{Non-response and multiple imputation}

Students were allowed to declare that they were not willing to answer certain questions considered sensitive, such as suicidal thoughts, PPS, personal history of depression or attempted suicide, parental divorce, parental death, and not living in the parental home in childhood. These refusals were coded as missing data. The literature shows the value of imputing in case of missing data rather than excluding them [20]. It also highlights the pitfalls associated with misuse of this method [21] such as making a false assumption of missingness at random. It is therefore advisable to present the two results of these analyses and to compare them. Thus, in the main analysis, participants with missing data were excluded in order to present a complete data analysis. Then we performed a sensitivity analysis with multiple imputation on missing data in order to take into account non-response among eligible students. We chose the method known as multiple imputation by chained equation (MICE). This method was based on an algorithm of the Monte Carlo Markov chain method, which was adapted for imputation on arbitrary or non-monotonic data [22]. First, we analyzed the shape of the refusal data; then we formulated the assumption of missing-at-random data. We hypothesized that the typology of the non-response data was informative, and that it did not occur completely at random, because it reflected the student's unwillingness to answer. Therefore, according to this method, we assumed that all the information on the missing data was contained in the observed data. This method assumes that the distributions of the incomplete variables are conditional on the other variables of the imputation model. We performed 10 imputations. For each set of imputed data, we estimated the imputed model parameters by taking into account all variables of the chosen model.

\section{Attributable fraction}

The attributable fraction (AF) was defined as the proportion of suicidal thoughts attributable to PPS, calculated as follows [23]:

$$
\mathrm{AF}=\frac{p(R R-1)}{p(R R-1)+1}
$$

where $p$ represents the underlying prevalence of the risk factor (low PPS) in our population; i.e., the prevalence of low PPS levels (including questionnaire responses of moderate, low, or none) in our sample. $R R$ is the relative risk of suicidal thoughts in the exposed population (i.e., the population that described PPS as moderate, low, or none) divided by the risk of suicidal thoughts in the unexposed population (the population that described PPS as extremely strong, or strong). This calculation was also used to determine the AF for other family events measured in the study.

All $p$-values were two-tailed, and $p<0.05$ was considered statistically significant. Analyses were performed with SAS version 9.4 (SAS Institute Inc., Cray, NC, USA).

\section{Results}

\section{Sample description based on suicidal thoughts}

Of the 11,968 students that fully completed the questionnaire, 720 were excluded because they were not between 18 and 24 years of age. Another 1223 (11\%) were excluded because they were not willing to answer questions related to suicidal thoughts, PPS, and confounding variables (Fig. 1). For all variables, excluded non-respondents comprised less than $4 \%$ (range: 1 to $4 \%$ ). Participants were allowed to refuse to answer the question regarding parental history of depression or anxiety. In this case, a rather large number of individuals $(n=1045,10 \%)$ refused to respond; therefore, we decided to include this group of participants in the analyses. The final study population included 10,015 students.

Compared to the 10,015 included participants, the 1233 excluded students that did not answer the questions of interest reported more occasional $(n=208,25.6 \%$ vs. $n=$ $1775,17.7 \%)$ and frequent ( $n=77,9.5 \%$ vs. $n=368,3.7 \%$, $p<0.0001)$ suicidal thoughts. Additionally, compared to included students, the excluded students were more likely to describe PPS as "none" and to respond "yes" to a personal history of depression, attempted suicide, or negative childhood events (Table 1). 


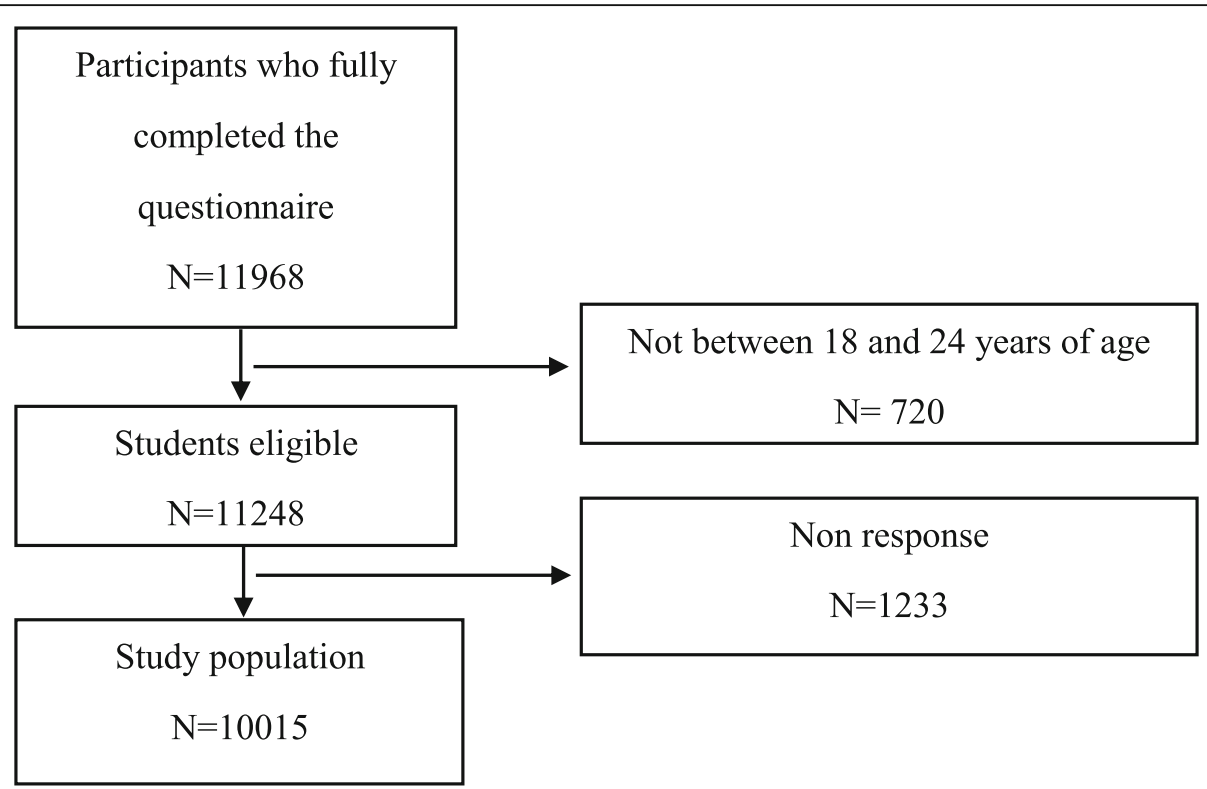

Fig. 1 Flow chart of the study population (i-Share cohort, 2013-2017)

Table 1 Comparison of key variables between participants and nonparticipants*

\begin{tabular}{|c|c|c|c|}
\hline Characteristic & Participants $(n=10,015)$ & Nonparticipants ( $n=1233)$ & $p^{* *}$ \\
\hline Age, mean (SD) & $20.0(1.8)$ & $19.7(1.7)$ & $<.0001$ \\
\hline Female, No. (\%) & $7579(75.7)$ & $935(75.8)$ & 0.904 \\
\hline Parental divorce or separation, No. (\%) & $3114(31.1)$ & $349(40.4)$ & $<.0001$ \\
\hline Parental death, No. (\%) & $376(3.8)$ & $145(14.2)$ & $<.0001$ \\
\hline Did not live in parental home during childhood, No. (\%) & $196(2.0)$ & $73(6.1)$ & $<.0001$ \\
\hline Perceived economic status in childhood, No. (\%) & & & $<.0001$ \\
\hline Adequate to very comfortable & $9193(91.8)$ & $1024(83.1)$ & \\
\hline Difficult to very difficult & $822(8.2)$ & $209(17.0)$ & \\
\hline Parental history of depression, No. (\%) & $3925(43.8)$ & $478(54.2)$ & \\
\hline Personal history of depression or attempted suicide, No. (\%) & $1274(13.7)$ & $242(24.7)$ & $<.0001$ \\
\hline Suicidal thoughts, No. (\%) & & & $<.0001$ \\
\hline No & $7872(78.6)$ & $529(65.0)$ & \\
\hline Occasional & $1775(17.7)$ & $208(25.6)$ & \\
\hline Frequent & $368(3.7)$ & $77(9.5)$ & \\
\hline Perceived parental support, No. (\%) & & & $<.0001$ \\
\hline Extremely strong & $3277(32.7)$ & $250(23.9)$ & \\
\hline Strong & 4065 (40.6) & $372(35.6)$ & \\
\hline Moderate & $1907(19.0)$ & $265(25.3)$ & \\
\hline Low & $610(6.1)$ & $120(11.5)$ & \\
\hline None & $156(1.6)$ & $39(3.7)$ & \\
\hline
\end{tabular}

*Data are from the i-Share cohort, 2013-2017

${ }^{* *} \mathrm{P}$-Values are based on Kruskall-Wallis test for continuous variables and the $\mathrm{Chi}^{2}$ test for categorical variables 
In our sample, 7872 (78.7\%) students reported no suicidal thoughts. About one student in five reported suicidal thoughts in the past 12 months; of these, 1775 (17.7\%) had occasional suicidal thoughts and 368 (3.7\%) had frequent suicidal thoughts.

Table 2 shows the sample characteristics, both overall and categorized by the type of suicidal thoughts. The mean age of the participants was 20.0 years $( \pm 1.8)$ and about three quarters were female $(n=7539 ; 75.7 \%)$. Participants with occasional and frequent suicidal thoughts were more likely to declare negative family events, such as parental divorce $(p<0.0001)$ or parental death $(p=$ $0.0004)$, compared to those with no suicidal thoughts. They were more likely scholarship holder $(p<0.0001)$ and to declare an economic status in childhood as difficult to very difficult $(p<0.0001)$. Students that declared suicidal thoughts also reported more parental history of depression or anxiety than those with no suicidal thoughts. A personal history of depression or attempted suicide was reported by more than half the students with frequent suicidal thoughts $(n=216 ; 58.7 \%)$, about a third of those with occasional suicidal thoughts $(n=496$; $27.9 \%$ ), and less than $10 \%$ of those without suicidal thoughts $(n=662 ; 8.4 \%, p<0.0001)$.

The proportion of participants that reported strong PPS (including extremely strong and strong) declined as the frequency of suicidal thoughts increased $(p<0.0001)$.
Conversely, the proportion of participants that reported weak PPS (including questionnaire responses of moderate, low, and none) increased with increases in the frequency of suicidal thoughts. Thus, a total lack of PPS was more common among participants with frequent suicidal thoughts $(n=28 ; 7.6 \%)$ than among those with occasional suicidal thoughts $(n=56,3.2 \%)$ or those without suicidal thoughts $(n=72,0.9 \%)$.

\section{Association between PPS in childhood and adolescence and suicidal thoughts over the preceding year}

Table 3 summarizes the unadjusted and adjusted multinomial logistic model results. We observed a negative association between PPS and suicidal thoughts. The unadjusted univariate multinomial logistic regression also showed that lower levels of PPS were associated with higher frequencies of suicidal thoughts. Moreover, having a total lack of PPS (questionnaire response: 'none') strongly increased the odds of having suicidal thoughts occasionally (OR, 5.77; 95\% CI: 4.00-8.32) and frequently (OR, 8.38 ; 95\% CI: 11.08-30.48), compared to having an extremely strong PPS (Table 3 ).

A multiple adjustment to the model reduced the estimated values, but they remained relatively high. Thus, a total lack of PPS showed aORs of 4.43 for occasional suicidal thoughts (95\% CI: 3.02-6.49) and 9.81 for frequent suicidal thoughts (95\% CI: 5.60-17.19). In all models, we

Table 2 Characteristics of the study sample categorized by the frequency of suicidal thoughts over the preceding year ${ }^{*}$

\begin{tabular}{|c|c|c|c|c|c|}
\hline Characteristic & $\begin{array}{l}\text { All students } \\
(n=10,015)\end{array}$ & $\begin{array}{l}\text { No suicidal thoughts } \\
(n=7872)\end{array}$ & $\begin{array}{l}\text { Occasional suicidal } \\
\text { thoughts }(n=1775)\end{array}$ & $\begin{array}{l}\text { Frequent suicidal } \\
\text { thoughts }(n=368)\end{array}$ & $p^{* * *}$ \\
\hline Age, mean (SD) & $20.0(1.8)$ & $20.0(1.8)$ & $20.0(1.8)$ & $19.9(1.8)$ & 0.5081 \\
\hline Female, No. (\%) & $7579(75.7)$ & $5926(75.3)$ & $1366(77.0)$ & $287(78.0)$ & 0.1895 \\
\hline Parental divorce or separation, No. (\%) & $3114(31.1)$ & $2342(29.8)$ & $633(35.7)$ & $139(37.8)$ & $<0.0001$ \\
\hline Parental death, No. (\%) & $376(3.8)$ & $274(3.5)$ & $75(4.2)$ & $27(7.3)$ & 0.0004 \\
\hline Did not live in parental home during childhood, No. (\%) & $196(2.0)$ & $136(1.7)$ & $45(2.5)$ & $15(4.1)$ & 0.0010 \\
\hline Perceived economic status in childhood, No. (\%) & & & & & $<0.0001$ \\
\hline Adequate to very comfortable & $9193(91.8)$ & $7297(92.7)$ & $1730(97.5)$ & $353(95.9)$ & \\
\hline Difficult to very difficult & $822(8.2)$ & $575(7.3)$ & $191(10.8)$ & $56(15.2)$ & \\
\hline Scholarship, No. (\%) & $3810(38.0)$ & $2904(36.9)$ & $745(42.0)$ & $161(43.8)$ & $<0.0001$ \\
\hline Half time or more job activities, No. (\%) & $590(5.90)$ & $447(5.7)$ & $123(6.9)$ & $20(5.4)$ & $<0.0001$ \\
\hline Parental history of depression or anxiety, No. (\%) ${ }^{* *}$ & 3925 (43.8) & 2835 (39.8) & $885(57.7)$ & $205(65.3)$ & $<0.0001$ \\
\hline Personal history of depression or attempted suicide, No. (\%) & $1374(13.7)$ & $662(8.4)$ & $496(27.9)$ & $216(58.7)$ & 0.1204 \\
\hline Perceived parental support, No. (\%) & & & & & $<0.0001$ \\
\hline Extremely strong & $3277(32.7)$ & $2835(36.0)$ & $382(21.5)$ & $60(16.3)$ & \\
\hline Strong & 4065 (40.6) & 3275 (41.6) & $693(39.0)$ & $97(26.4)$ & \\
\hline Moderate & 1907 (19.0) & $1336(17.0)$ & $450(25.4)$ & $121(32.9)$ & \\
\hline Low & $610(6.1)$ & $354(4.5)$ & $194(11.0)$ & 62 (16.9) & \\
\hline None & 156 (1.6) & $72(0.9)$ & $56(3.2)$ & $28(7.6)$ & \\
\hline
\end{tabular}

*Data are from the i-Share cohort, 2013-2017

${ }^{* *} n=8970$, due to missing data

${ }^{* * *} P$ Values are based on Kruskall-Wallis test for continuous variable and $\mathrm{Chi}^{2}$ test for categorical variables 
Table 3 Associations between perceived parental support in childhood and adolescence and the frequency of suicidal thoughts over the preceding year ${ }^{*}$

\begin{tabular}{|c|c|c|c|c|c|c|}
\hline \multirow{3}{*}{$\begin{array}{l}\text { Perceived parental } \\
\text { support }\end{array}$} & \multicolumn{2}{|c|}{ Unadjusted $(n=10,015)$} & \multicolumn{2}{|c|}{ Adjusted $^{* *}(n=10,015)$} & \multicolumn{2}{|c|}{ Adjusted $^{* * *}(n=8970)$} \\
\hline & $\begin{array}{l}\text { Occasional suicidal } \\
\text { thoughts }\end{array}$ & $\begin{array}{l}\text { Frequent suicidal } \\
\text { thoughts }\end{array}$ & $\begin{array}{l}\text { Occasional suicidal } \\
\text { thoughts }\end{array}$ & $\begin{array}{l}\text { Frequent suicidal } \\
\text { thoughts }\end{array}$ & $\begin{array}{l}\text { Occasional suicidal } \\
\text { thoughts }\end{array}$ & $\begin{array}{l}\text { Frequent suicidal } \\
\text { thoughts }\end{array}$ \\
\hline & OR $(95 \% \mathrm{Cl})$ & OR $(95 \% \mathrm{Cl})$ & OR $(95 \% \mathrm{Cl})$ & OR $(95 \% \mathrm{Cl})$ & OR $(95 \% \mathrm{Cl})$ & OR $(95 \% \mathrm{Cl})$ \\
\hline Extremely strong & 1.00 & 1.00 & 1.00 & 1.00 & 1.00 & 1.00 \\
\hline Strong & $1.57(1.37-1.80)$ & $1.40(1.01-1.94)$ & $1.55(1.35-1.78)$ & $1.35(0.96-1.88)$ & $1.55(1.34-1.79)$ & $1.23(0.86-1.74)$ \\
\hline Moderate & $2.50(2.15-2.91)$ & $4.27(3.12-5.87)$ & $2.26(1.93-2.64)$ & $3.40(2.44-4.74)$ & $2.11(1.78-2.49)$ & $2.90(2.05-4.11)$ \\
\hline Low & $4.08(3.31-5.00)$ & $8.28(5.70-12.00)$ & $3.39(2.73-4.19)$ & $5.35(3.60-7.95)$ & $3.33(2.64-4.20)$ & $4.91(3.23-7.47)$ \\
\hline None & $5.77(4.00-8.32)$ & $18.38(11.08-30.48)$ & $4.43(3.02-6.49)$ & $9.81(5.60-17.19)$ & $4.55(2.97-6.99)$ & $8.58(4.62-15.96)$ \\
\hline
\end{tabular}

OR odds ratio, $\mathrm{Cl}$ confidence interval.

*Data from the i-Share cohort, 2013-2017.

**Adjusted for age, gender, parental divorce or separation, parental death, not living in parental homeduring childhood, perceived economic status in childhood, and personal history of depression or attemptedsuicide.

***Adjusted for age, gender, parental divorce or separation, parental death, not living in parental home during childhood, perceived economic status in childhood, personal history of depression or attemptedsuicide, and parental history of depression or anxiety

observed that the PPS was negatively associated with the risk of suicidal thoughts. Further adjusting with the parental history of depression or anxiety did not change the general interpretation of the results (Table 3).

We tested interactions between gender and perceived parental support and it was not significant ( $p$ for interaction $=0.40$ ). To investigate whether there was a statistically significant interaction between PPS and a personal history of depression or attempted suicide, we performed a stratified regression analysis. The risks of both occasional and frequent suicidal thoughts increased with decreases in the level of PPS in both strata, but the risks were higher among students without a personal history of depression or attempted suicide ( $p$ for interaction < 0.001; Table 4). For example, a total lack of PPS was associated with a 6-fold risk of frequent suicidal thoughts (aOR, 6.01; 95\% CI: 2.65-14.00) among students with a personal history of depression or attempted suicide, but the risk was eight-fold (aOR, 8.06; 95\% CI: 2.92-22.23) for students without a personal history of depression or attempted suicide.

When the model was tested after adding multiple imputations of non-response data, we found that the relative efficiency of the imputation on each of the variables was greater than $95 \%$. This finding indicated that the number of imputations was sufficient for the fraction of non-response data. The estimations obtained from the imputed model were close to those obtained from the non-imputed model (Table 5). The association between PPS and suicidal thoughts was statistically significant for all models $(p<0.05)$ except in the multiple imputation models for the students without history of depression or suicide attempt.

We also found that the risks associated with PPS were higher than the risks associated other negative childhood events measured in our study (Table 6), independent of the adjustment. This was confirmed by the calculation of attributable risk. We found that $20.5 \%$ of occasional and frequent suicidal thoughts could be attributed to an insufficient PPS (frequency of PPS rated 'moderate,' 'low', or 'none' in our sample: $26 \%$ ), which was the same percentage $(20.5 \%)$ attributed to a personal history of depression or attempted suicide (frequency of personal history of depression or attempted suicide in our sample: $13.7 \%)$. Both these percentages were notably higher than the percentage of suicidal thoughts attributed to parental divorce $(6.9 \%)$ or parental death (1.1\%).

\section{Discussion}

In this cross-sectional study on a large sample of 10,015 students, we found a strong association between PPS in childhood and adolescence and suicidal thoughts in young adults. Lower levels of PPS were associated with a higher frequency of both occasional and frequent suicidal thoughts. Thus, a total lack of PPS was associated with more than 4-fold increased risk of occasional suicidal thoughts (aOR, 4.55; 95\% CI: 2.97-6.99) and nearly 9-fold increased risk of frequent suicidal thoughts (aOR, 8.58; 95\% CI: 4.62-15.96). In all models, we observed a negative association between the level of PPS and the frequency of suicidal thoughts. Sensitivity analyses modifying adjustment and multiple imputation modeling provided consistent results.

Few studies have described the association between PPS and suicidal thoughts in young adults, and most did not control for confounding factors related to the family environment. In one study that included 5183 Chinese students, suicidal ideation was associated with poor family structures and relationships or improper parenting styles [24]. In another study that included 188 African American students, strong family support was associated with a lower incidence of suicide ideation [25]. Similarly, in a Taiwanese study that included 2919 college students, a positive linear trend was observed between increased 





Table 5 Associations between perceived parental support and suicidal thoughts in an adjusted multinomial logistic regression model after multiple imputation for non-response data*

\begin{tabular}{|c|c|c|c|c|c|c|}
\hline \multirow{4}{*}{$\begin{array}{l}\text { Perceived parental } \\
\text { support }\end{array}$} & \multicolumn{2}{|c|}{ Adjusted $^{* *}(n=11,248)$} & \multicolumn{4}{|c|}{ Adjusted model ${ }^{* * *}(n=11,248)$} \\
\hline & \multirow{3}{*}{$\begin{array}{l}\text { Occasional suicidal } \\
\text { thoughts } \\
\text { OR }(95 \% \mathrm{Cl})\end{array}$} & \multirow{3}{*}{$\begin{array}{l}\text { Frequent suicidal } \\
\text { thoughts } \\
\text { OR }(95 \% \mathrm{Cl})\end{array}$} & \multicolumn{2}{|c|}{$\begin{array}{l}\text { Personal history of depression or attempted } \\
\text { suicide }\end{array}$} & \multicolumn{2}{|c|}{$\begin{array}{l}\text { No personal history of depression or attemptec } \\
\text { suicide }\end{array}$} \\
\hline & & & $\begin{array}{l}\text { Occasional suicidal } \\
\text { thoughts }\end{array}$ & $\begin{array}{l}\text { Frequent suicidal } \\
\text { thoughts }\end{array}$ & $\begin{array}{l}\text { Occasional suicidal } \\
\text { thoughts }\end{array}$ & $\begin{array}{l}\text { Frequent suicidal } \\
\text { thoughts }\end{array}$ \\
\hline & & & OR $(95 \% \mathrm{Cl})$ & OR $(95 \% \mathrm{Cl})$ & OR $(95 \% \mathrm{Cl})$ & OR $(95 \% \mathrm{Cl})$ \\
\hline Extremely strong & 1.00 & 1.00 & 1.00 & 1.00 & 1.00 & 1.00 \\
\hline Strong & $1.49(1.30-1.70)$ & $1.30(0.96-1.76)$ & $1.17(0.72-1.90)$ & $1.53(0.52-4.51)$ & $1.60(1.38-1.86)$ & $1.10(0.72-1.68)$ \\
\hline Moderate & $2.13(1.83-2.47)$ & $2.92(2.15-3.96)$ & $1.32(0.78-2.24)$ & $2.51(0.86-7.34)$ & $2.40(2.02-2.86)$ & $3.05(2.00-4.66)$ \\
\hline Low & $3.05(2.49-3.73)$ & $5.17(3.60-7.41)$ & $1.64(0.81-3.35)$ & $4.07(1.15-14.43)$ & $3.74(2.91-4.80)$ & $5.86(3.48-9.85)$ \\
\hline None & $4.07(2.85-5.80)$ & $8.54(5.10-14.31)$ & $1.69(0.53-5.40)$ & $5.93(0.87-9.97)$ & $5.68(3.75-8.61)$ & $8.83(3.90-20.03)$ \\
\hline
\end{tabular}

$O R$ odds ratio, $\mathrm{Cl}$ confidence interval

*Data from the i-Share cohort, 2013-2017

${ }^{* *}$ Adjusted for age, gender, parental divorce or separation, parental death, not living in parental home during childhood, perceived economic status in childhood, personal history of depression or attempted suicide, and parental history of depression or anxiety

***Adjusted for age, gender, parental divorce or separation, parental death, not living in parental home during childhood, perceived economic status in childhood, perceived parental support $\times$ personal history of depression or attempted suicide, and parental history of depression or anxiety

suicidal tendency and a parenting style with low affection [26]. In a younger age range (adolescents 12 to 18 years old), it was shown that inadequate social and family support increased the risk of suicide or suicidal ideation [27-31]. Similarly, a cross-sectional study that included 448 adolescents aged 13 to 17 years measured PPS with the Perceived Social Support from Family Scale. In that study, each one point increase in PPS was associated with a $54 \%$ lower frequency in suicidal plans [32]. Compared to the present study, all those previous studies were more focused on current parental support, in addition to other social determinants. However, a longitudinal study conducted among a large sample of adolescents showed conflicting results. Parental support was predictive of lower levels of depression but was not significantly associated with the outcomes related to suicidal behaviors [33].

The present study had some important strengths, including the size of the sample, the strength of the associations, the PPS-dose-dependent pattern, the consistency of our results with previous studies, and the large number of variables collected and adjusted for in the multivariable models. Furthermore, when we performed multiple imputation for non-response data and the sensitivity analysis, we found consistent results. However, there were also some limitations in this study. First, it was a cross-sectional analysis; therefore, we could not strictly separate the timing of exposure, outcome, and covariates. Moreover, no causality could be inferred between PPS and suicidal ideation. Second, only brief and succinct measures could be done in large sample studies and perceived parental support as well as suicidal ideation were assessed with only one item. This is a limitation that has to be taken into account when interpreting our results. However, the prevalence of suicidal thoughts found in our study fall within the range reported by the main studies on the subject $[4-6,8]$ which was somehow reassuring. Third, the voluntary participation of students may have introduced a self-selection bias, although it is difficult to see how this potential bias could have influenced the observed associations. Fourth, the information was self-reported, which could lead to an information bias, particularly if participants under-reported the frequency of suicidal thoughts or the presence of a personal and/or family history, due to considerations of social acceptability. Again, this under-reporting would be expected to have a low impact on the associations observed. Fifth, there is an over-representation of women in our sample compared to the $56 \%$ of female students in France. However, we tested interactions with gender for the main analyses and none was significant. Further, in stratified analyses, aOR did not differ significantly between males and females and the confidence intervals were largely overlapping (data not shown). Finally, although we had information on confounding factors, we could not rule out the influence of residual or unmeasured confounding factors, due to the complexity of the suicidal thought process. In addition, because our predictor variable was PPS, a recall bias might have led to an overestimation of the associations between support and suicidal ideation. However, our findings on the differential roles that PPS played for students with and without a history of depression suggested that a recall bias might have had limited effect. Indeed, we postulated that, if recall bias was a major source of influence, the association between low support and suicidal thoughts would be stronger in students with a history of depression compared to those without. Instead, we found the reverse; students without a history of depression were more likely to report suicidal thoughts, when they also reported low parental support during childhood and adolescence. 
Table 6 Association between student characteristics and suicidal thoughts ${ }^{*}$

\begin{tabular}{|c|c|c|c|c|}
\hline \multirow[t]{3}{*}{ Characteristic } & \multicolumn{2}{|l|}{ Unadjusted $(n=10,015)$} & \multicolumn{2}{|l|}{ Adjusted $^{* *}(n=8970)$} \\
\hline & Occasional suicidal thoughts & Frequent suicidal thoughts & Occasional suicidal thoughts & Frequent suicidal thoughts \\
\hline & OR $(95 \% \mathrm{Cl})$ & OR $(95 \% \mathrm{Cl})$ & OR $(95 \% \mathrm{Cl})$ & OR $(95 \% \mathrm{Cl})$ \\
\hline Age & $1.01(0.98-1.04)$ & $0.97(0.92-1.03)$ & $0.99(0.96-1.02)$ & $0.91(0.85-0.97)$ \\
\hline \multicolumn{5}{|l|}{ Gender } \\
\hline Male & 1.00 & 1.00 & 1.00 & 1.00 \\
\hline Female & $1.10(0.97-1.24)$ & $1.16(0.90-1.50)$ & $1.01(0.88-1.16)$ & $0.82(0.62-1.10)$ \\
\hline \multicolumn{5}{|l|}{ Parental divorce or separation } \\
\hline No & 1.00 & 1.00 & 1.00 & 1.00 \\
\hline Yes & $1.31(1.17-1.46)$ & $1.43(1.16-1.78)$ & $0.89(0.78-1.01)$ & $0.81(0.62-1.05)$ \\
\hline \multicolumn{5}{|l|}{ Parental death } \\
\hline No & 1.00 & 1.00 & 1.00 & 1.00 \\
\hline Yes & $1.22(0.94-1.59)$ & $2.20(1.46-3.31)$ & $1.08(0.80-1.45)$ & $1.75(1.07-2.88)$ \\
\hline \multicolumn{5}{|c|}{ Did not live in parental home during childhood } \\
\hline No & 1.00 & 1.00 & 1.00 & 1.00 \\
\hline Yes & $1.48(1.05-2.08)$ & $2.42(1.40-4.17)$ & $1.07(0.72-1.58)$ & $1.21(0.63-2.32)$ \\
\hline \multicolumn{5}{|c|}{ Perceived economic status in childhood } \\
\hline Correct to very comfortable & 1.00 & 1.00 & 1.00 & 1.00 \\
\hline Difficult to very difficult & $1.53(1.29-1.82)$ & $2.28(1.70-3.07)$ & $1.10(0.90-1.35)$ & $1.21(0.63-2.32)$ \\
\hline \multicolumn{5}{|c|}{ Parental history of depression or anxiety } \\
\hline No & 1.00 & 1.00 & 1.00 & 1.00 \\
\hline Yes & $2.06(1.84-2.31)$ & $2.84(2.24-3.60)$ & $1.59(1.41-1.80)$ & $1.59(1.22-2.08)$ \\
\hline \multicolumn{5}{|c|}{ Personal history of depression or attempted suicide } \\
\hline No & 1.00 & 1.00 & 1.00 & 1.00 \\
\hline Yes & $4.22(3.71-4.81)$ & $15.48(12.40-19.33)$ & $3.63(3.13-4.20)$ & $11.68(9.06-15.07)$ \\
\hline \multicolumn{5}{|l|}{ Perceived parental support } \\
\hline Extremely strong & 1.00 & 1.00 & 1.00 & 1.00 \\
\hline Strong & $1.57(1.37-1.80)$ & $1.40(1.01-1.94)$ & $1.55(1.34-1.79)$ & $1.23(0.86-1.74)$ \\
\hline Moderate & $2.50(2.15-2.91)$ & $4.27(3.12-5.87)$ & $2.11(1.78-2.49)$ & $2.90(2.05-4.11)$ \\
\hline Low & $4.08(3.31-5.00)$ & $8.28(5.70-12.00)$ & $3.33(2.64-4.20)$ & $4.91(3.23-7.47)$ \\
\hline None & $5.77(4.00-8.32)$ & $18.38(11.08-30.48)$ & $4.55(2.97-6.99)$ & $8.58(4.62-15.96)$ \\
\hline
\end{tabular}

$O R$ odds ratio, $\mathrm{Cl}$ confidence interval

*Data from the i-Share cohort, 2013-2017

**Adjusted for age, gender, parental divorce or separation, parental death, not living in parental home during childhood, perceived economic status in childhood, personal history of depression or attempted suicide, and parental history of depression or anxiety

We found that our estimation of the risk associated with PPS was higher than previous estimated risks of other variables known to be associated with suicidal ideation, such as parental divorce [34, 35] or parental death $[36,37]$. We also noted that the specific role of low PPS could not be distinguished from the roles of other negative parenting practices, such as abuse or neglect (not measured in our study). However, our associations remained significant after controlling for other negative childhood events, such as parental death or divorce.

The association between PPS and suicidal thoughts could reflect a familial aggregation of suicidal thoughts and mood disorders. Contributors to his type of aggregation might be unknown psycho-social, clinical, or biological factors, including genetic factors [38]; for example, parents that provide low support might be experiencing depression [39].

Our results in young adults, if confirmed by other studies, could eventually lead to the development of intervention programs for families at an early stage of life and thus be a prerequisite for more targeted, less costly and more effective prevention interventions [40]. In adolescents, such programs have yielded promising results to decrease the incidence of suicidal thoughts in young adults after an intervention started in adolescence [41, 42]. These interventions, aimed 
primarily at building parenting support and supervision capacities, are strategies developed by the CDC in suicide prevention [43]. Other programs such as attachment-based family therapy [44] aim to transform the quality of adolescent-parent attachment in order to provide the adolescent with a safer relationship that can support him during difficult times and crises related to suicidal thoughts and behaviors.

Regardless of the subjectivity of the PPS variable or the etiology of suicidal thoughts, evaluating PPS could be useful in assessments of suicidal risk in young adults. Given that PPS is a relatively neutral, non-intrusive variable, health professionals can readily assess PPS to improve suicide risk screening. Our findings indicated that PPS could be a particularly important marker, because the association between PPS and suicidal ideation was stronger in the absence than in the presence of a personal history of attempted suicide or depression. This is remarkable, because a personal history of attempted suicide or depression is an important marker of suicidal risk. Our findings highlighted the importance of interventions that aim to screen for and correct risky situations that children might face at home.

To summarize, our results indicated that a low PPS in childhood and adolescence was strongly associated with frequent suicidal thoughts in young adults. This issue should be systematically addressed in further clinical studies on suicidal risk in young people and, if confirmed, it could be considered in routine care. Longitudinal studies should assess the ability of PPS to predict the risk of suicide attempts and suicide.

\section{Abbreviations \\ AF: Attributable fraction; Cl: Confidence interval; CNIL: Commission nationale de l'informatique et des libertés - National Commission of Informatics and Liberties; i-Share: Internet-based Students' Health Research Enterprise; MICE: Multiple imputation by chained equation; OR: Odds ratio; PPS: Perceived parental support; RR: Relative risk; SD: Standard deviation; WHO: World health organization}

\section{Acknowledgments}

The authors are grateful to the coordinating team of the i-Share project for their assistance in setting up and collecting data. In particular, we would like to thank: Clotilde Pollet, Edwige Pereira, Sarah Qchiqach, Elena Milesi, and Marie Mougin. We thank all the students that participated in the i-Share study.

\section{Funding}

This work was supported by the French National Research Agency (Agence nationale de la Recherche) via the program "Investissements d'Avenir", grant ANR-10-COHO-05. The funding sponsor played no role in the design of the study; in the collection, analyses, or interpretation of data; in writing the manuscript; or in the decision to publish the results.

\section{Availability of data and materials}

The datasets used and/or analyzed during the current study are available from the corresponding author on reasonable request.

\section{Authors' contributions}

MM, CT, and SC designed the study. MM and AS conducted the statistical analysis. MM and CT wrote the first draft of the manuscript. All co-authors had full access to the data, read, revised, and approved the final manuscript.

\section{Ethics approval and consent to participate}

The i-Share project was approved by the "Commission nationale de l'informatique et des libertés" (National Commission of Informatics and Liberties, Reference DR-2013-019). Students were informed on the nature and purpose of the study and provided on-line consent.

\section{Consent for publication}

Not applicable

\section{Competing interests}

The authors declare that they have no competing interests.

\section{Publisher's Note}

Springer Nature remains neutral with regard to jurisdictional claims in published maps and institutional affiliations.

\section{Author details}

${ }^{1}$ Inserm, Bordeaux Population Health Research Center, University of Bordeaux, UMR 1219, F-33000 Bordeaux, France. ${ }^{2}$ Charles Perrens Hospital, Bordeaux, France. ${ }^{3}$ University of Montreal, Montreal, Québec, Canada. ${ }^{4}$ University of Bordeaux, 146 rue Léo Saignat, 33076 Bordeaux Cedex, Bordeaux, France.

Received: 25 June 2018 Accepted: 16 November 2018

Published online: 27 November 2018

\section{References}

1. World Health Organization (WHO). Suicide data. 2017. http://www.who.int/ mental_health/prevention/suicide/suicideprevent/en/. Accessed 19 Feb 2018.

2. Centers for Disease Control and Prevention (CDC). 2015. Web-based Injury Statistics Query and Reporting System (WISQARS). https://www.cdc.gov/ violenceprevention/suicide/statistics/. Accessed 15 Jan 2018.

3. Schwartz AJ. College student suicide in the United States: 1990-1991 through 2003-2004. J Am Coll Heal. 2006;54(6):341-52.

4. Garlow SJ, Rosenberg J, Moore JD, et al. Depression, desperation, and suicidal ideation in college students: results from the American Foundation for Suicide Prevention College screening project at Emory University. Depress Anxiety. 2008;25(6):482-8.

5. Wilcox HC, Arria AM, Caldeira KM, Vincent KB, Pinchevsky GM, O'Grady KE. Prevalence and predictors of persistent suicide ideation, plans, and attempts during college. J Affect Disord. 2010;127(1-3):287-94.

6. Arria AM, O'Grady KE, Caldeira KM, Vincent KB, Wilcox HC, Wish ED. Suicide ideation among college students: a multivariate analysis. Arch Suicide Res. 2009;13(3):230-46.

7. Brener ND, Hassan SS, Barrios LC. Suicidal ideation among college students in the United States. J Consult Clin Psychol. 1999;67(6):1004-8.

8. Mortier P, Cuijpers P, Kiekens G, Auerbach RP, Demyttenaere K, Green JG, et al. The prevalence of suicidal thoughts and behaviours among college students: a meta-analysis. Psychol Med. 2018;48(4):554-65.

9. Reinherz HZ, Giaconia RM, Silverman AB, Friedman A, Pakiz B, Frost AK. al. Early psychosocial risks for adolescent suicidal ideation and attempts. J Am Acad Child Adolesc Psychiatry. 1995;34(5):599-611.

10. Brent DA, Johnson B, Bartle S, Bridge J, Rather C, Matta J, et al. Personality disorder, tendency to impulsive violence, and suicidal behavior in adolescents. J Am Acad Child Adolesc Psychiatry. 1993;32(1):69-75.

11. Van Orden KA, Witte TK, Cukrowicz KC, Braithwaite S, Selby EA, Joiner TE. The interpersonal theory of suicide. Psychol Rev. 2010;117(2):575-600.

12. Brent DA, Mann JJ. Family genetic studies, suicide, and suicidal behavior. Am J Med Genet C Semin Med Genet. 2005;133 C(1):13-24.

13. Bridge JA, Brent DA, Johnson BA, Connolly J. Familial aggregation of psychiatric disorders in a community sample of adolescents. J Am Acad Child Adolesc Psychiatry. 1997;36(5):628-36.

14. King CA, Kerr DCR, Passarelli MN, Foster CE, Merchant CR. One-year followup of suicidal adolescents: parental history of mental health problems and time to post-hospitalization attempt. J Youth Adolesc. 2010;39(3):219-32. 
15. Morano CD, Cisler RA, Lemerond J. Risk factors for adolescent suicidal behavior: loss, insufficient familial support, and hopelessness. Adolescence. 1993;28(112):851-65.

16. Kang B-H, Kang J-H, Park H-A, Cho Y-G, Hur Y-I, Sim WY. al. The mediating role of parental support in the relationship between life stress and suicidal ideation among middle school students. Korean J Fam Med. 2017:38(4):213-9.

17. Sharaf AY, Thompson EA, Walsh E. Protective effects of self-esteem and family support on suicide risk behaviors among at-risk adolescents. J Child Adolesc Psychiatr Nurs. 2009;22(3):160-8.

18. Czyz EK, Liu Z, King CA. Social connectedness and one-year trajectories among suicidal adolescents following psychiatric hospitalization. J Clin Child Adolesc Psychol. 2012;41(2):214-26.

19. World Health Organization (WHO). Young people and health: challenge for society. 2003 health: challenge for society. 2003 health: challenge for society. 2003. http://whqlibdoc.who.int/trs/WHO_TRS_731_fre.pdf. Accessed 22 Jan 2018.

20. Janssen KJ, Donders ART, Harrell FE Jr, Vergouwe Y, Chen Q, Grobbee DE, Moons KG. Missing covariate data in medical research: to impute is better than to ignore. J Clin Epidemiol. 2010;63(7):721-7.

21. Sterne JA, White IR, Carlin JB, Spratt M, Royston P, Kenward MG, Carpenter JR. Multiple imputation for missing data in epidemiological and clinical research: potential and pitfalls. BMJ. 2009;338:b2393.

22. Faris PD, Ghali WA, Brant R, Norris CM, Galbraith PD, Knudtson ML, et al. Multiple imputation versus data enhancement for dealing with missing data in observational health care outcome analyses. J Clin Epidemiol. 2002;55(2): 184-91.

23. Rosen $\mathrm{L}$. An intuitive approach to understanding the attributable fraction of disease due to a risk factor: the case of smoking. Int J Environ Res Public Health. 2013;10(7):2932-43.

24. Zhai H, Bai B, Chen L, Han D, Wang L, Qiao Z, et al. Correlation between family environment and suicidal ideation in university students in China. Int J Environ Res Public Health. 2015;12(2):1412-24.

25. Harris TL, Molock SD. Cultural orientation, family cohesion, and family support in suicide ideation and depression among african american college students. Suicide Life Threat Behav. 2000;30(4):341-53.

26. Gau SS-F, Chen Y-Y, Tsai F-J, Lee M-B, Chiu Y-N, Soong W-T, et al. Risk factors for suicide in Taiwanese college students. J Am Coll Heal. 2008;57(2): $135-42$.

27. Barzilay S, Brunstein Klomek A, Apter A, Carli V, Wasserman C, Hadlaczky G, et al. Bullying victimization and suicide ideation and behavior among adolescents in Europe: a 10-country study. J Adolesc Health. 2017;61(2): 179-86.

28. Joiner TE. Why people die by suicide. Cambridge: Harvard University press; 2005.

29. King CA, Merchant CR. Social and interpersonal factors relating to adolescent suicidality: a review of the literature. Arch Suicide Res. 2008;12(3): 181-96.

30. Miller AB, Esposito-Smythers C, Leichtweis RN. Role of social support in adolescent suicidal ideation and suicide attempts. J Adolesc Health. 2015; 56(3):286-92.

31. Kerr DCR, Preuss $\amalg$, King CA. Suicidal adolescents' social support from family and peers: gender-specific associations with psychopathology. J Abnorm Child Psychol. 2006;34(1):103-14.

32. Klaus NM, Mobilio A, King CA. Parent-adolescent agreement concerning adolescents' suicidal thoughts and behaviors. J Clin Child Adolesc Psychol. 2009;38(2):245-55.

33. LeCloux M, Maramaldi P, Thomas KA, Wharff EA. A longitudinal study of health care resources, family support, and mental health outcomes among suicidal adolescents. Anal Soc Issues Public Policy. 2017;17(1):319-38. https://doi.org/10.1111/asap.12139.

34. Lindström M, Rosvall M. Parental separation in childhood, social capital, and suicide thoughts and suicide attempts: a population-based study. Psychiatry Res. 2015;229(1-2):206-13.

35. De Goede M, Spruijt E. Effects of parental divorce and youth unemployment on adolescent health. Patient Educ Couns. 1996;29(3): 269-76.

36. Rostila M, Berg L, Arat A, Vinnerljung B, Hjern A. Parental death in childhood and self-inflicted injuries in young adults-a national cohort study from Sweden. Eur Child Adolesc Psychiatry. 2016;25(10):1103-11.

37. Guldin M-B, Li J, Pedersen HS, Obel C, Agerbo E, Gissler M, et al. Incidence of suicide among persons who had a parent who died during their childhood: a population-based cohort study. JAMA Psychiatry. 2015;72(12): 1227-34.

38. Turecki G, Brent DA. Suicide and suicidal behavior. Lancet. 2016;387(10024): 1227-39.

39. Taraban L, Shaw DS, Leve LD, Natsuaki MN, Ganiban JM, Reiss D, et al. Parental depression, overreactive parenting, and early childhood externalizing problems: moderation by social support. Child Dev. 2018. https://doi.org/10.1111/cdev.13027.

40. Heckman JJ. Skill formation and the economics of investing in disadvantaged children. Science. 2006;312(5782):1900-2.

41. Reider EE, Sims BE. Family-based preventive interventions: can the onset of suicidal ideation and behavior be prevented? Suicide Life Threat Behav. 2016;46(Suppl 1):S3-7.

42. Connell AM, McKillop HN, Dishion TJ. Long-term effects of the family checkup in early adolescence on risk of suicide in early adulthood. Suicide Life Threat Behav. 2016;46:S15-22.

43. Centers for Disease Control and Prevention (CDC). 2017. https://www.cdc. gov/violenceprevention/suicide/prevention.html. Accessed 10 Oct 2018.

44. Ewing ESK, Diamond G, Levy S. Attachment-based family therapy for depressed and suicidal adolescents: theory, clinical model and empirical support. Attach Hum Dev. 2015;17(2):136-56.
Ready to submit your research? Choose BMC and benefit from:

- fast, convenient online submission

- thorough peer review by experienced researchers in your field

- rapid publication on acceptance

- support for research data, including large and complex data types

- gold Open Access which fosters wider collaboration and increased citations

- maximum visibility for your research: over $100 \mathrm{M}$ website views per year

At BMC, research is always in progress.

Learn more biomedcentral.com/submissions 